This item was submitted to Loughborough's Research Repository by the author.

Items in Figshare are protected by copyright, with all rights reserved, unless otherwise indicated.

\title{
Practitioner understanding of value in the UK Building Sector
}

PLEASE CITE THE PUBLISHED VERSION

http://dx.doi.org/10.1108/09699981311323970

PUBLISHER

(C) Emerald

VERSION

AM (Accepted Manuscript)

LICENCE

CC BY-NC-ND 4.0

REPOSITORY RECORD

Thomson, Derek S., Simon A. Austin, Grant R. Mills, and Hannah Devine-Wright. 2019. "Practitioner Understanding of Value in the UK Building Sector”. figshare. https://hdl.handle.net/2134/11719. 
This item was submitted to Loughborough's Institutional Repository (https://dspace.lboro.ac.uk/) by the author and is made available under the following Creative Commons Licence conditions.

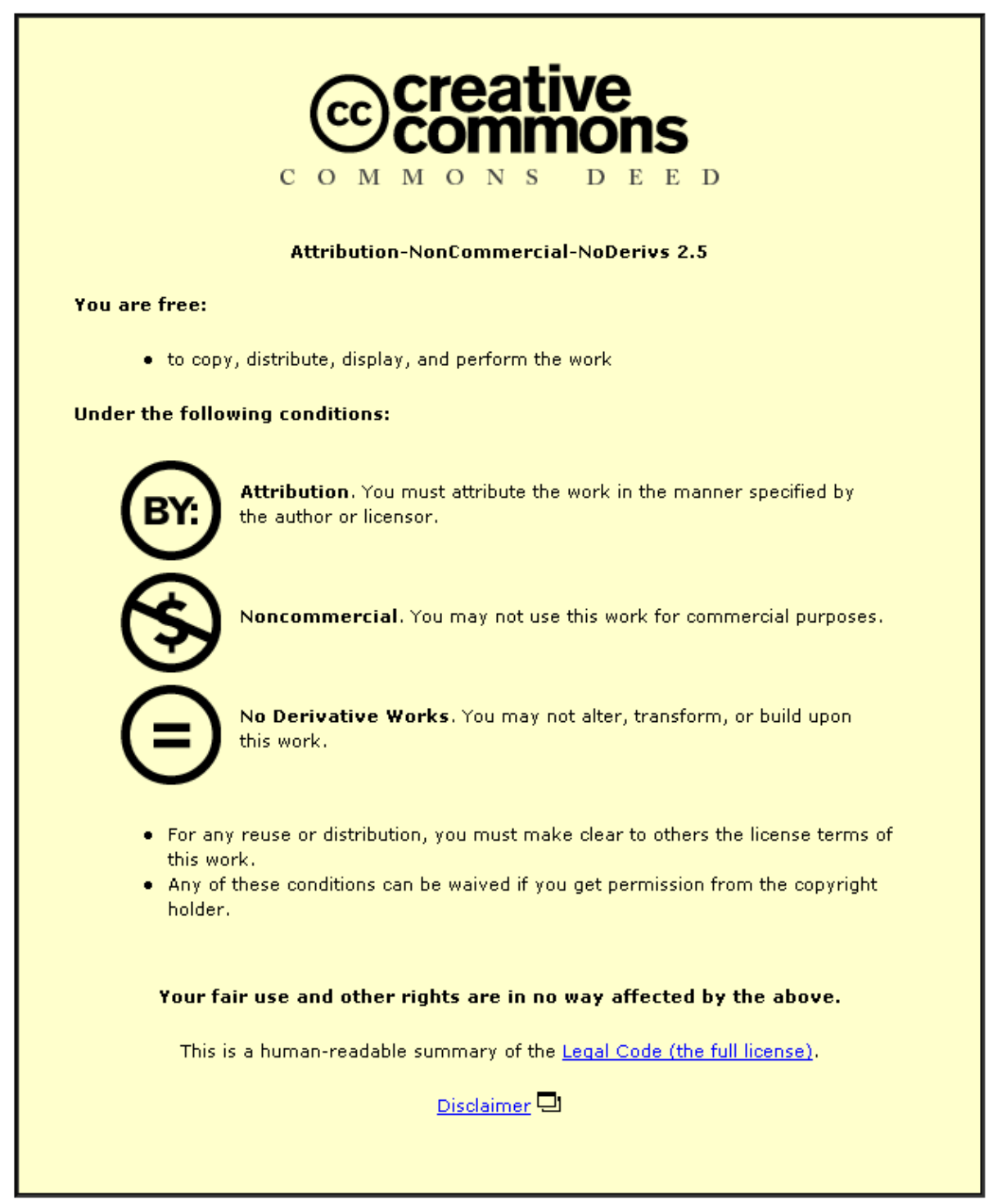

For the full text of this licence, please go to: http://creativecommons.org/licenses/by-nc-nd/2.5/ 


\title{
Practitioner Understanding of Value in the UK Building Sector
}

Derek S. Thomson, Simon A. Austin, Grant R. Mills, Hannah Devine-Wright

\begin{abstract}
Purpose: For over a decade, UK public sector construction policy and industry rhetoric has advanced a value agenda that advocates the development of project-specific understanding of value. This study examines construction practitioners' collective cognition of value to determine how their facilitation may bias this intent. A value continuum is contributed.

Design/methodology/approach: Critique of the Design Quality Indicator (the primary value agenda instrument) finds that it overemphasises objective value, confirming the need for practitioners to help stakeholders develop broader understanding of value. The freelisting technique of cultural anthropology is used to model practitioners' collective cognition of value and, thus, their bias over this process. The standard freelisting protocol is followed.
\end{abstract}

Findings: Practitioners' collective understanding is found to comprise related concepts that resolve to a one dimensional 'value continuum' with subjective and objective terminals and which fully embodies value agenda intent. In contrast, the concepts articulated by the Design Quality Indicator are biased towards the objective value continuum terminal, confirming the need for practitioners to facilitate stakeholder exploration of the full continuum if the value agenda is to be fully addressed.

Research limitations/implications: The value continuum only reflects the views of a small but typical sample of construction practitioners. Further work must characterise model completeness and consistency through the supply chain.

Originality/value: This is the first work to derive an empirical model of construction practitioners' collective understanding of value. It achieves this by the novel linking of a cognitive modelling technique from cultural anthropology with an emic interpretation of the results.

\section{Keywords}

Value theory; design quality indicator; building design; stakeholder engagement; value continuum

\section{Introduction}

Since the turn of the century, sustained debate among UK construction industry practitioners and clients has questioned the value that new buildings offer their stakeholders. A 'value agenda' 
emerged from government and industry rhetoric that placed stakeholder interpretation at the centre of what building value could be. This led to the promotion of exemplar building qualities and development of the Design Quality Indicator (DQI) as an instrument to structure building evaluation against a standardised definition of 'good' building qualities. The originators of the DQI noted that, if used alone, it may limit stakeholder debate to a reductionist view of desired, or even permitted, qualities. Fully addressing the value agenda requires construction industry practitioners to use the DQI "as a starting point for discussion" (Gann et al., 2003: 332) among stakeholders from which debate of building qualities would build common, per-project understanding of building value.

The project forum through which client and practitioner jointly understand the client's requirements and views of value is pivotal to the delivery of buildings that fulfil value agenda intent. The forum accommodates the activities that need to be performed to create commercial or societal value. With this in mind, the DQI provides a 'tool for thinking' to help practitioners and stakeholders "reflect upon their contributions to the overall design of a building" (Gann et al., 2003: 332) in the course of building that understanding. At least; this was the intent of its originators.

This study questions the understanding of value that practitioners contribute to the dialogue surrounding DQI use on individual projects. This is important as, through their facilitating role, the practitioner frames the mutual understanding of value developed among stakeholders. In the following discussion, the understanding of 'value' collectively held by sample practitioners is modelled using the freelisting technique from cultural anthropology. The resulting model of this cultural domain is then interpreted to determine the presence of value agenda principles. The authors undertook this investigation with the premise that the DQI considers building value to result from design compliance with a prescribed set of building qualities. Although compatible with the tenets of axiology (Hartman, 1967) and Vitruvian notions of 'good' (Vitruvius, 2001), such an objective view of value (Thyssen, 2011) may not be appropriate if, ignoring O'Keeffe et al.'s (2011) questioning of the compliance model itself, the notion of 'good' embodied in the DQI does not reflect practitioners' understanding of value.

\section{The value agenda}

For over a decade, central UK Government has advocated the creation of buildings that provide 'value' beyond functional and financial performance. Through policy and the advocacy of the former Commission for Architecture and the Built Environment (now Design Council CABE), UK Government sought 'better' designed buildings (Eley, 2004; Gann et al., 2003). For example, rather than necessarily being provided for lowest cost, hospitals were expected to make patients feel good to speed their recovery (Centre for Healthcare Design, 2002; CABE, 2006); schools were expected to inspire children to learn (CABE, 2007, 2010); housing developments were expected to nurture cohesive communities (Westbury, 2007); private sector commercial developments were expected to embrace public access to privately-owned space (Mulgan, 2005); and so on. These efforts, in which buildings were considered more than mere modifiers of environment, came to be known as the 'value agenda.' 
The value agenda considered value to exist in the relationship between people and buildings. It was considered a property of both, yet a property of neither alone. The agenda melded subjective and objective views of extrinsic and intrinsic value in a "mixture of tangible and intangible benefits" (Spencer and Winch, 2002). Implicit within the agenda was the intent that building features (namely, qualities) would be interpreted by each stakeholder and, framed by their values, yield a perception of value.

In the austerity era following the change of UK government in May 2010, the value agenda's project-specific debate of value was depreciated in favour of standardised designs, systematised construction techniques, and greater focus on cost reduction. The Building Schools for the Future programme was cancelled (Nikkhah, 2011), for example, and the National Health Service was directed to replicate proven design solutions rather than directly responding to stakeholder expectations (Rogers, 2010).

Despite this new policy, the core instrument of the value agenda - the Design Quality Indicator (DQI) - remains embedded in mandated public sector procurement methods. It also continues to be advocated for private sector and international adoption, where it has had some success (Keniger, 2004; Zemke and Pullman, 2008).

\section{Understanding 'Better' Buildings}

The value agenda did not explicitly define the 'value' it promoted. Instead, it established broad tenets of 'good design' through the promotion exemplar projects that offered value in ways that, while being unique to their stakeholders and context, possessed qualities considered transferrable to other projects. This promotion of exemplar good buildings and their qualities aped the principles of Alexander et al.'s pattern language (1977) and were expressed by CABE (2005) as "Design Coding." By advocating the recreation prescribed building qualities, this notion of value embodied the philosophical notion of 'good' (Dent, 2005). The principle that a building can possess an ideal form and therefore be 'good' reflects Hartman's (1967) view that "a thing has value in the degree that it fulfils the intension of its concept." By emphasising the importance of the qualities - namely, the physical and performance attributes - of buildings, the value agenda expressed a view of value that had parallels with the principles of aesthetic axiology. The evaluation of building qualities mirrored "the activity of measuring the properties of things by intention (sets of predicates) to see if they fulfil or fail to fulfil their concepts" (Edwards, 2010: 133) found in that discipline. However, as Thyssen (2011: 54) noted, although the presence of sought qualities in an object yields intrinsic value, these patterns cannot be simply replicated between projects. The appropriateness and adaptation of patterns to their observer and context must always be considered as extrinsic value is also important (ibid).

As the central instrument of the value agenda, the DQI embodies an aspirational definition of what 'good' buildings should be by defining the qualities all buildings are expected to exhibit. The DQI adopts Vitruvius' (2001) definition of good, expressing the firmness ('firmitas'), commodity ('utilitas') and delight ('venustas') of an ideal building as 'build quality,' 'functionality' and 'impact' (Gann et al., 2003). While this generic construct structures stakeholder judgements of the presence of qualities, the ability of these qualities to fully represent the value sought from an individual project must be questioned. 
Merely replicating generic qualities does not afford an opportunity to consider the qualities that the stakeholders of a given project require to meet their specific needs, in their specific situation. Instead, it reduces the consideration of 'value' to expressing the relevance of generic qualities to their situation. The DQI systematically imposes its generic definition of 'good' upon projects through its fixed evaluation structure. A building that is not generically ideal may suit the specific needs of a group of stakeholders causing it to offer the best value to them, yet it would be considered of low quality by a DQI evaluation. The reductionist approach of the DQI precludes the dialectic consideration of value that would allow a definition of 'good' to be composed for each project.

The importance of practitioners' professional expertise and their ability to make judgements about value in particular, is emphasised by Volker et al. (2008) as a necessary response to an over-reliance on reductionist instruments. They observe a reliance upon such instruments among practitioners who fear litigation for non-compliance with prescribed procurement mechanisms, even when those mechanisms conflate the meaningful consideration of "intangible as well as tangible aspects of design quality" (Volker et al., 2008: 389) into a simple auditable decision making process. O'Keeffe et al. (2011) mirror this observation, having found that a healthcare-specific DQI derivative 'short-circuits' stakeholder engagement in design development; as design quality becomes associated with simple compliance to a prescribed ideal and process rather than an exploration of a project-specific understanding of value. Dewulf and Meel highlight the "scientifically muddy waters" (2004: 248) of attempting to measure subjective building qualities. Moreover, the regimen of the DQI instils a mentality of procedure compliance rather than privileging the substantive understanding of value. This creates a tendency towards the "tick box syndrome" that has befallen the value management discipline (Male et al., 2007: 112).

These shortcomings in the ability of the DQI to guide meaningful debate of required building qualities and the value they must realise increases dependency on the practitioner's ability to articulate the concept. The practitioner's understanding of value is therefore critical to the effective administration of the DQI as it empowers that practitioner to create a context for instrument use by leading stakeholders through discussion of value to reveal and understand their unique expectations before attempting to express them in a DQI evaluation. This departure from a solely-objective view of value has previously been articulated as a way to help stakeholders "gain a better understanding of their own requirements and to communicate them effectively to the design team" (Green and Moss, 1998: 35). Such an approach may, for example, allow project stakeholders to understand which aspects of the DQI definition of 'good' are important for their project, rather than attempting to satisfy all its components.

To ensure that value is offered by buildings, practitioners must establish and sustain an adaptive, 'judgement-based' model of design quality evaluation and value realisation. Gann and Whyte (2003) claimed that the DQI achieved this, yet Volker et al. (2008) characterised the DQI in use as merely 'rational-adaptive' because it "accepts that quality is a difficult and uncertain aspect to measure" (ibid: 390). The DQI must, therefore, be augmented with a practitioner-led stakeholder dialogue through which stakeholder understanding of value must be elicited and agreed. 


\section{The Impact of the Value Agenda}

The sustained value agenda rhetoric may have caused practitioners' understanding of value to unduly focus on realising generic qualities rather than stimulating dialogue with stakeholders to determine the appropriateness of those qualities to a specific building and move from an objective to subjective view of value. As a situated, interpretative phenomenon each stakeholder judges value by relating their latent construct (i.e. tacit understanding) of value to a projectspecific situation (e.g. design proposals). Practitioners must facilitate dialogue to accommodate the stakeholder sensemaking necessary to elicit the multiple perspectives of value present within a project (Leiringer et al., 2009). Practitioners must then guide stakeholders in the social construction of a shared understanding of 'value' to help them establish project-specific priorities.

Moreover, if stakeholders lack construction experience (as most do), a dialogue may develop between stakeholders' aspirations and the practitioner's practical knowledge of construction, resulting in the co-creation of an understanding of value. This is reflected in the shift of many contracting organisations to an 'integrated project delivery' business model (e.g. Thyssen et al., 2010; Kemmer et al., 2011) aligned with the service-dominant logic and mutual dependency of value co-creation (Vargo et al., 2008). Transforming practitioner facilitation of stakeholder debate into the co-creation of expectation of value may also allow practitioners to inject an understanding of value that extends beyond UK value agenda tenets. Such direction of stakeholder debate would be viable if practitioners possess a more nuanced understanding of value beyond the compliance model of the DQI.

Alternative characterisations of value may be present within practitioners' collective understanding due to influences other than the value agenda such as their education and experience. These can be grouped into four broad 'schools' of value cognition: the compliance school of axiology; the definition school of value analysis and value management; the transformation and alignment school of lean production; and the dual creation-consumption school of co-creation.

In axiology, where value is considered to result from reproducing 'ideal' attributes of a class of an object (Hartman, 1967; Rescher 2004), value is associated with the recreation of perfect form. Value is considered absolute and is governed by values of the society in which a philosophically 'good' object can exist. Among those who apply axiology to construction, Thyssen (2011) and Kelly (2007) suggest that value can be subjectively or objectively considered. They emphasise the latter suggesting that '"goodness' and 'beauty' are objective values of which nobody could disapprove" Thyssen et al. (2010: 19).

The principle of attribute reproduction to create 'good' buildings is a central tenet of the DQI, in which 'attributes' are 'qualities' within the impact, function and delight Vitruvian triad. Barima takes a similar view of project performance, suggesting that value results from the successful delivery of sought "project end delivery attributes" (2009: 875), providing a link to the transformation view of value (or, more specifically, the value-adding value stream analysis and lean production) by suggesting this can be achieved by well-developed project processes. These views also align with one of the conceptualisations of value held by the Austrian School as they 
imply that an object can have an intrinsic value, or Eigenwert (Böhm-Bawerk, 1973: 121), irrespective of its observer. However, the axiological view as currently articulated in construction ignores the more pivotal tenet of the Austrian School to which "economic value belongs exclusively" (Böhm-Bawerk, 1973: 122): that objects also have value due to the Wirkungswert that results from their ability to be used as means to an end; for intended purposes. Smith (1948) terms the value that results from using objects in this way "utility value." This association of value with purpose is the fundamental principle of value analysis.

Around the same time as axiological views of value were developing, Miles invented the functional perspective of value analysis to consider the purpose of proposed design elements so that their intended value (only considered as 'use value' in this context) could be understood and realised by adopting more readily available or less costly alternatives (Kelly and Male, 1993). In this school, value is considered to result from the relationship of function to cost or, more specifically, the cost of providing sought functions. This provides an indirect connection with utility and use value in that benefit to the client is considered.

In construction, this focus on functionality has operationalised as a structured pattern of project interventions (Male et al. 1998), each in turn structured around a well-understood 'Job Plan' (Miles, 1961) to provide a creative problem solving process through which stakeholders are led to develop an analytical understanding of value through what has come to be known as "value management" in many Westernised countries (Kelly et al. 2004). More recent Western developments have seen the production of the Value Methodology (SAVE International, 2007) and the EU Value Management standard (British Standards Institution, 2000) to frame value as the delivery of functionality to support a client's ongoing business development. This may, or may not, entail the creation of buildings or infrastructure.

In the lean production arena, Womack and Jones (2003) define value as the delivery of a product that meets the customer's needs at a given price and time. This production-oriented view (Slack, 1999) merely defines value as the absence of waste; and suggests that it results from the careful alignment of production stages to produce an optimised value stream (Arbulu et al., 2003) through which production flows. Focusing on the transformation of material or information as it flows through such a process, this understanding of value attempts to align activities to ensure the output of a preceding activity is exactly that required by the next. This gives a dual customer model in which one customer is purchasing the product delivered by to the customer by the value stream, while the other comprises those implementing adjacent stream activities. These two expectations of value can be quite different.

When lean production principles are applied to construction, connections to quality (and intrinsic value) emerge aligned with Pirsig's (1974) and Sennett (2008)'s views of the praxis by which a craftsman embodies their understanding of quality and value in an object through their skilled and purposeful action. Lindhard and Wandahl (2012) typify more overt view of value by, although implicitly acknowledging this praxis, underplaying it in preference for a positivist approach to production scheduling. In this case, the sophistication of understanding of value is limited. 
Finally, in recent work Jahani and El-Gohary (2012) have attempted to prescribe a taxonomy of 'value' for representation in BIM models, mirroring the deterministic approach of the DQI 's attempt to bridge the absolutes of axiology's compliance model of value with the judgements and experiences of co-creation's consumption model. This approach and is, therefore, unlikely to adequately articulate the concept because it fails to respond to the project-specific understandings of value that co-creation emphasises.

Recent thinking considers value to be 'co-created' by the combined actions of consumer and producer to create a service with the latter instantaneously experiencing and judging it (Vargo and Lusch, 2008). This service-dominant (s-d) logic (Vargo et al., 2008) view shares the Austrian School contention that value is created in use rather than exchange. The co-creation school is distinguished from those prior by considering value to only exist in the active participation of both producer and customer. The value engineering and lean construction schools adopted a production view in which the customer's needs were considered sufficiently coherent and predictable that a project outcome could be developed to offer a value proposition that, upon object use after a delivery process (such as the elongated delivery of a building) would satisfy those needs. This brief-create-consume model characterises current industry practice yet, cocreators would contend, fails to realise value.

Co-creation considers value to be formed at the intersection of production and consumption. A subjective view of use value therefore dominates, causing the objective view of axiology to become untenable. However, although prominent in the rhetoric of co-creation, value itself remains a loosely defined construct: merely being considered vaguely as 'benefit' to both producer and consumer (Payne et al., 2007; Vargo et al., 2008). Grönroos suggests that this broad definition of value implies that it is not related to use but to some, as yet unknown, "overarching value construct" (2011: 280). This work searches for such a construct in practitioners' collective understanding.

\section{Research Premise}

The interactions of practitioner and stakeholders form an "organizational climate" (Nicolini, 2002: 168) in which common understanding develops. This internal culture allows practitioners' understanding of value to be characterised using analytical methods from cultural anthropology. With this cultural perspective, practitioners' collective understanding of value was considered a cultural domain following Weller and Romney's (2009: 9) definition of words, sentences and concepts that "jointly refer to a single conceptual sphere" and which has an internal structure in the relationship of its constituent concepts (Borgatti and Halgin, 2011). These concepts were observed and interpreted to determine the presence, or otherwise, of value agenda principles within collective practitioner understanding. This study of practitioners' collective, tacit understanding of value was directed by the following research question:

"Does construction practitioners' collective understanding of value reflect the intent of the value agenda, the content of the design quality indicator, or something else?" 


\section{Data Gathering}

To accurately elicit each practitioner's latent construct of 'value,' a data gathering mechanism with minimal framing of construct expression was required. This was found in the "deceptively simple, but powerful" Bernard (2006: 301) 'freelisting' method used by cultural anthropologists to elicit cultural domain content (Schrauf and Sanchez, 2008). Among its varied applications, freelisting has: characterised understanding acquired via education (e.g. Ares and Deliza, 2010); differentiated or defined cultural groups (e.g. Winkler-Rhoades et al., 2010, Uusküla and Sutrop, 2007); revealed consumer understanding of brands (Crowe and Prescott, 2003); and, in construction projects, elicited intangible benefits sought from buildings (Thomson et al., 2012). In all these applications, the method minimised framing by simply asking practitioners to freely recall the words they associate with a stated cultural domain. The resulting word lists were analysed to reveal the associations between concepts that characterise collective understanding.

Freelisting was administered per Figure 1. After eliciting the terms that each participant individually associated with the cultural domain of 'value,' collective modelling commenced with data reduction by term harmonisation to expose underlying concepts, after which salience analysis was performed. Following the standard protocol usefully summarised by Bernard and Ryan (2010), cluster analysis then identified related concepts around which an explanatory model was inferred.

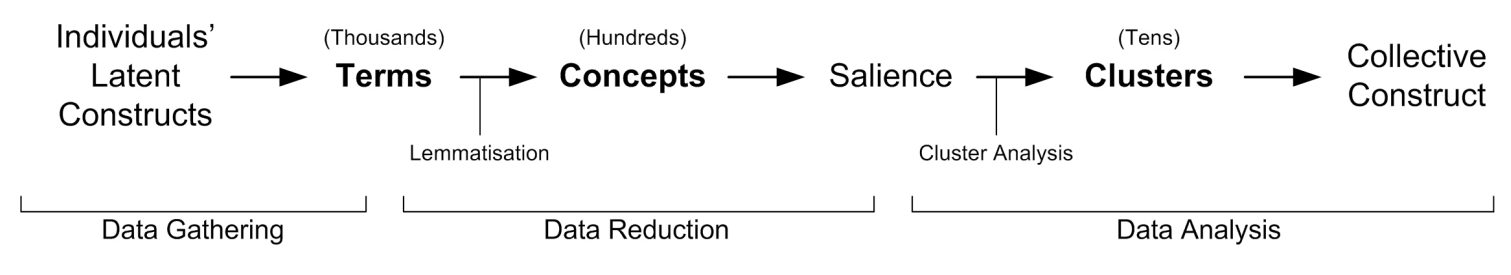

Figure 1: The Freelisting Protocol

A purposive convenience sample was sought by targeting experienced construction practitioners drawn from multi-disciplinary contracting organisations, consulting organisations and academics offering consultancy services related to value (Table 1). Data were gathered when ethically sound opportunities presented themselves in the academics' ongoing work. These included live project scenarios such as value management workshops. Data gathering activity ceased after 41 anonymous participants formed a representative sample of practitioners engaged in building projects. 


\begin{tabular}{lcc} 
Practitioner Role & Number & $\begin{array}{c}\text { Sample } \\
\text { Proportion }\end{array}$ \\
\hline Academic & 3 & $7 \%$ \\
\hline Architect & 12 & $29 \%$ \\
\hline Client / Client Representative & 3 & $7 \%$ \\
\hline Construction Cost or Commercial Consultant & 8 & $20 \%$ \\
\hline Contractor & 2 & $5 \%$ \\
\hline Property Manager / Facilities Manager & 7 & $17 \%$ \\
\hline Services Engineer / Building Engineer & 6 & $15 \%$ \\
\hline
\end{tabular}

Table 1: Sample Composition

Although an individual activity, freelisting was undertaken in workshop settings to ensure consistent instruction and task duration. Each data gathering episode commenced with issue of an information sheet describing the principles of freelisting. Participants were given the opportunity to decline to participate. As the freelisting sessions were often 'piggybacked' onto a workshop or meeting convened for another, albeit value-related purpose, two individuals declined, citing a perceived lack of relevant experience although no rationale for non-participation was requested.

Along with the consent form, a pro-forma for capturing responses and elicitation prompt was distributed and placed face-down in front of the participants. To ensure the "exact same question [was] asked of the entire sample of respondents" (Borgatti and Halgin, 2011), Bousfield and Barclay's (1950) original elicitation prompt format - which continues to be used today - was adapted, viz.:

"When you think about value in the construction industry, write down a single word for each additional, related thought that comes into your mind."

With a ten minute elicitation period, the 41 participants yielded 2,274 terms (a word or phrase describing a concept). Following Brewer's protocol (1995, 1995b), initial data reduction removed repetitions of a term in a list to retain only the first expression; reducing the data to 1,546 terms.

The generalised freelisting protocol then harmonises freelists before analysing their collective structure. Prototype theory was used to build idealised terminology by acknowledging that several terms can represent the same concept. For example, in a built environment context, Volker (2010:17) asserts that 'qualities', 'traits,' 'attributes' and 'characteristics' are synonymous. This was a manual process analogous to the lemmatisation of natural language processing. Working from an emic perspective informed by their experience as a construction practitioner, the analyst identified synonymous terms expressing a common underlying concept. All the terms describing each concept were represented by their most descriptive term and placed at the most prominent (i.e. earliest) list position. As non-lemmatised lists contained many repeated concepts (as opposed to the repeated terms removed in the previous step), harmonisation reduced 1,546 terms to 440 distinct concepts. 
Freelisting uses list position and frequency to define collective concept 'salience' within the cultural domain. Adopting Sutrop's view that "passive use" terms (2001: 265) are clearly not salient, concepts elicited from only one participant were removed. This further reduced the dataset from 440 to 210 concepts. Sutrop's salience index was calculated for the remaining terms to "combine the frequency and mean position of a term into one parameter" (2001: 267). The most salient terms were identified by scree plot, with the 15 terms present before the knee (Figure 2, Table 2) "represent[ing] the contents of the domain" (Bernard and Ryan, 2010: 168). These were then forwarded to cluster analysis.

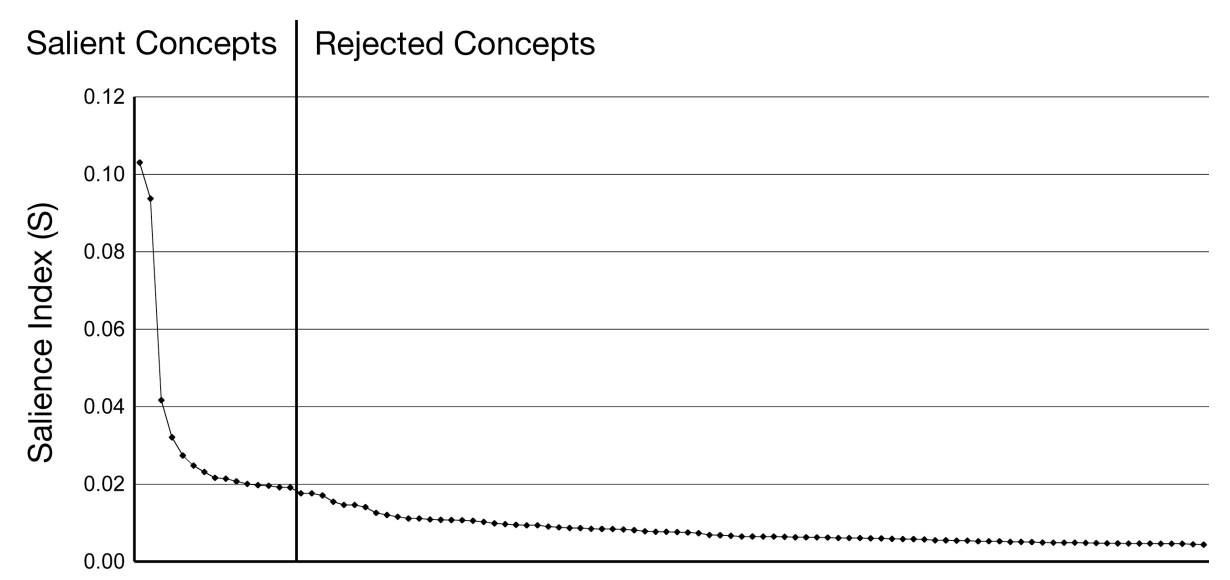

Elicited Concept, Ordered by Salience Index

Figure 2: Scree Plot of Concept Salience (only first 100 terms plotted for clarity)

\begin{tabular}{cc} 
Concept & Salience Index \\
\hline cost & 0.1030 \\
\hline quality & 0.0937 \\
\hline design & 0.0417 \\
\hline worth & 0.0321 \\
\hline durability & 0.0274 \\
\hline materials & 0.0248 \\
\hline functionality & 0.0232 \\
\hline time & 0.0216
\end{tabular}

\begin{tabular}{cc} 
Concept & Salience Index \\
\hline benefit & 0.0214 \\
\hline client & 0.0207 \\
\hline aesthetics & 0.0201 \\
\hline sustainable & 0.0197 \\
\hline market price & 0.0196 \\
\hline money & 0.0192 \\
\hline management & 0.0191 \\
\hline
\end{tabular}

Table 2: Salient Concepts

\section{Data Analysis and Results}

Following Brewer's (1995b: 262) observation that concepts "associat[ed] in recall by a given scheme or variable" will cluster, cluster analysis was used to reveal these associations so that the underlying cognitive scheme could be inferred. As Bousefield (1953) originally determined, concepts that are consistently close to each other in the collective elicitation sequence are cognitively associated. Cluster analysis exposed these associations as follows. The average 
normalised rank of each concept was calculated by dividing the sum of its normalised rank position on each participant's free list by its frequency. The absolute distance between all concepts was determined and an Euclidean distance matrix compiled in which distance represented dissimilarity. Descriptive agglomerative hierarchical cluster analysis and associative multidimensional scaling interrogated the resulting dissimilarity matrix.

Hierarchical agglomerative cluster analysis was implemented in the SPSS software package using the furthest neighbour method. This produced a hierarchy of clusters distinguished by their two most distant concepts to emphasise cluster differences. This yielded five clusters, as illustrated by Figure 3. The analysis was then repeated with the software additionally directed to group concepts into five clusters. This verified the cluster assignments as the same arrangement resulted.

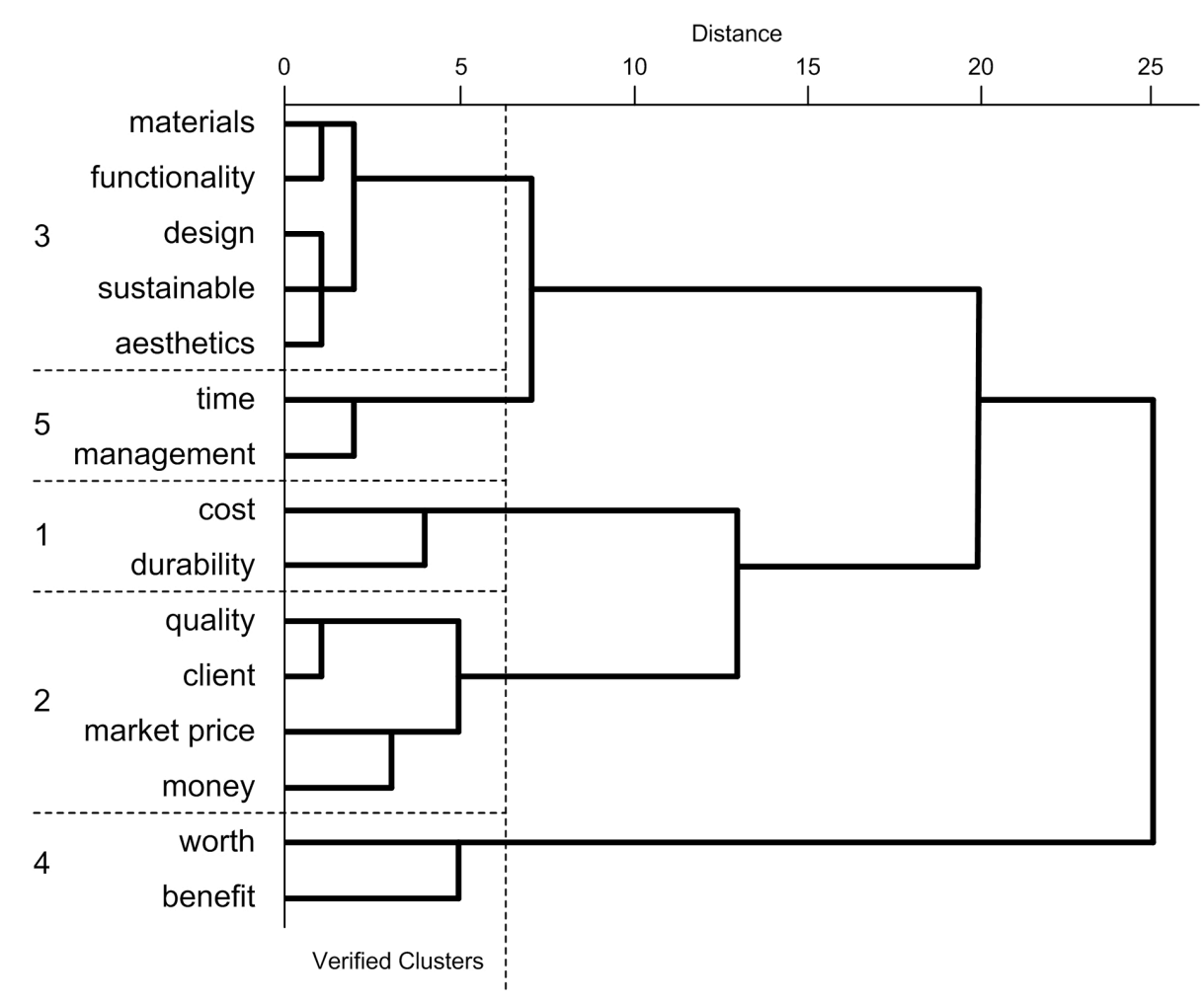

Figure 3: Dendrogram illustrating Concept Clustering

Agglomerative cluster analysis reveals cluster membership only. It does not establish the degree of association between clusters or between concepts within a cluster. To provide this insight, metric multidimensional scaling was used to spatially arrange concepts by their similarity to give the "best fit with the least number of possible dimensions" (Jaworska and ChupetlovskaAnastasova, 2009: 4). The dissimilarity matrix was processed using classical, metric multidimensional scaling as the dissimilarity distances represented ratio data. To associate the data with the lowest number of explanatory dimensions, the ALSCAL algorithm was configured to derive a spatial arrangement on two or fewer dimensions. The analysis determined that the variance between concepts could be fully accounted for with excellent goodness of fit (RSQ $=1$ ) 
and no residual stress (Kruskal's stress index $=0$ ) by a one-dimensional linear arrangement. The value continuum was revealed.

Recalling Figure 3, agglomerative analysis identified five clusters (Table 3). Informed by their emic view of the studied domain, the analyst - an experienced construction management researcher providing value management consultancy services to industry and previously a quantity surveyor practitioner - inferred the meaning of each cluster.

Cluster Role in Explanatory Model

\begin{tabular}{cl}
\hline 1 & The through-life cost consequences of construction project outcomes. \\
\hline 2 & $\begin{array}{l}\text { The market-facing monetary aspects of value, with particular focus on the } \\
\text { relationship between capital expenditure and asset quality. }\end{array}$ \\
\hline 3 & The building attributes considered evidence of value delivery. \\
\hline 4 & The judgement of construction project outcomes held by an individual. \\
\hline 5 & The management of the construction project. \\
\hline Note: & Refer to the Appendix for cluster content
\end{tabular}

Table 3: Inferred Cluster Meanings

Cluster 1 was interpreted as the relationship between capital expenditure and through-life building maintenance costs. As illustrated in the Appendix, the 'durability' concept clearly represented the expected lifespan of the building while 'cost' related to capital expenditure and, more specifically, its constraint by available budget. The 'cost' concept was notably more salient than terms within 'durability' despite their cognitive association.

Cluster 2 was considered a monetary component of value, with particular focus on asset market value. The presence of the concept of 'client' within this cluster was inferred as practitioners' acknowledgement that the procuring client funds most construction projects. The constituent concepts implied that clients can be considered willing to create a building if its market price and quality could be assured. Indeed, the association of 'quality' with this cluster aped the rudimentary 'iron triangle' brief-taking heuristic (Atkinson, 1999; Yu et al., 2005) that implies higher quality workmanship or design will command a higher 'market price' than normal fulfilment of these parameters.

The terms comprising Cluster 3 were inferred to be the building qualities that practitioners consider evidence of value provision. Recalling Figure 3, the hierarchical cluster analysis identified two sub-clusters within this cluster. The first, comprising 'materials' and 'functionality' was interpreted to represent building fitness for purpose as this is contingent on material specifications. The second, comprising the concepts of 'design,' 'sustainable' and 'aesthetics' was inferred to illustrate building traits considered desirable and, thus, related to value.

Cluster 4 was interpreted as that component of value most directly related to perception and judgement. This aspect of value is reflected in the principles of stated preference valuation methods (Pearce and Özdemiroglu, 2002), value function theory (Beinat, 1997) and benefits realisation (Thomson et al., 2011). These entail the valuation of intangible aspects of buildings; a 
fundamentally perceptual process subject to cognitive biases (Kahneman, 2011) and other framing effects (Kahneman and Tversky, 1979). This aspect of value was therefore characterised as being more concerned with the individual's perception and tacit framing biases than the object itself and thus represented the most subjective aspect of value.

The final cluster was inferred to represent project management. Having observed cost and quality in other clusters, the analyst interpreted the association of 'time' - the final component of the iron triangle triad - with 'management' as a representation of the work scheduling and sequencing activities of project managers. As illustrated by the Appendix, the concepts within the 'management' cluster were clearly related to the varied activities performed by the typical project manager.

\section{Discussion}

Multidimensional scaling derived an arrangement of value concepts on a single dimension which correlated their dissimilarity with the distance between them (Figure 4). This arrangement exposed an underlying bipolar characteristic of value. Following standard protocol, an explanation of the latent construct ordering practitioners' collective understanding of 'value' was inferred by interpreting the position of concepts in the arrangement.

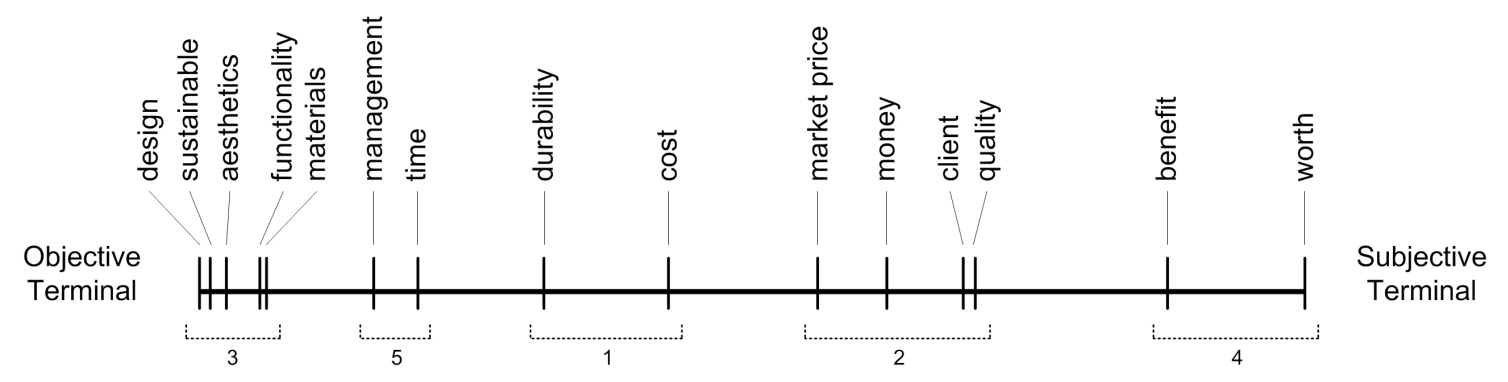

Figure 4: The Value Continuum, with Clusters Identified

Consideration of Cluster 3 suggested that the adjoining terminal was associated with physical building qualities ('materials'), building purpose ('functionality'), and building design traits through the presence of the 'design,' 'sustainable' and 'aesthetics,' concepts. Interpreted within the confines of the value agenda, these concepts formed a triad ('materials', 'functionality', 'design'/'sustainable'/'aesthetics') analogous to Vitruvius' model and, therefore, the DQI. The terminal adjacent to Cluster 3 was therefore considered to represent concepts associated with the valued object alone. The opposite terminal was defined by Cluster 4 . This cluster was interpreted to be associated with concepts of judgement ('benefit' and 'worth'): it represented the subject interpreting value rather than the building object being valued. The value continuum was therefore characterised as spanning the subject-object relationship, implying that value itself cannot be defined entirely from one perspective without consideration of the other.

The association of one terminal with an objective view of value and the other with a subjective view confirmed the presence of value agenda intent within practitioners' collective understanding. In contrast, the DQI was clearly cognitively associated with the objective 
terminal. This was interpreted as a consequence of the short-circuiting of meaningful consideration of value caused by mandated DQI use on public sector projects (O'Keeffe et al., 2011). This association has emerged despite the DQI creators' claim that quality "consists of both objective and subjective components" (Gann et al., 2003: 320). Indeed, this discrepancy suggests that value is a broader concept than quality, emphasising the importance of the practitioner's role in developing that broader understanding among stakeholders.

In 2003, Thomson et al. proposed a construction application of pure value theory that emphasised the transformative action of a construction project in changing stakeholders' situation. They reviewed explanations of value across multiple fields to synthesise a model that related the benefits that stakeholders seek from a project to the sacrifices they are willing to make to get that outcome. Concepts that can be interpreted as benefits were observed in practitioners' understanding ('worth,' 'benefit,' 'quality') as were sacrifices ('time,' 'cost,' 'money'), yet the diffusion of these concepts across the continuum suggested that they are not clearly differentiated on the underlying construct. There is, however, a clear association of aspects of value associated with "what the customer receives" (Thomson et al., 2003: 338) - 'quality, benefits, worth' (ibid) - as "benefits" and the subjective terminal. This can be interpreted as practitioners' appreciation that customer desires define necessary project outcomes. Evidence of practitioner appreciation of some of the sacrifices that stakeholders are willing to make to gain value is also present in the empirical model provided by this work ('money', 'cost,' 'time') but these are not clearly associated with either continuum terminal.

There is no evidence of embedding of concepts related to co-creation (such as mutual dependency of producer and customer or the instantaneous creation and consumption of value) in practitioners' current understanding of value. Evidence of the lean production view is minimal, although Cluster 5 ('management', 'time') could be construed to imply some awareness of the internal process customer. Moreover, the positioning of this cluster towards the objective terminal implies a distancing of this concept from the building customer. There is some evidence of the value agenda view of value in Cluster 3 ('design', 'functionality', 'materials') and these are entirely associated with the building object; as would be expected with the above critique of this school of value. Finally, although tenuous, it might be possible to say that some evidence of the axiological - specific aesthetic axiology - is also represented by the content and position of Cluster 3. Design resolutions of issues related to 'sustainable' and 'aesthetics' may be considered prerequisites to building value within the context of current societal values.

\section{Limitations}

This work has limitations. Although small, the sample size is appropriate to the freelisting technique (Bernard, 2006: 302-305). Weller and Romney suggest that only "20 to 30 informants" are sufficient to yield a coherent domain (2009:14), and this small sample size is commensurate with past studies (e.g. Schrauf and Sanchez, 2010; Uusküla and Sutrop, 2007). Freelisting is sometimes criticised for the potential of analyst bias in the lemmatisation stage (e.g. Thomson et al. 2011). This compromise is accepted in return for freelisting's particular ability to surface participants' tacit knowledge; a trait of the method that unfortunately also prohibits verifying triangulation. This further drawback is again accepted by users of the technique. 
Applicability of the findings is constrained by a sample skewed towards practitioners that design and construct buildings. Civil engineering projects are not represented, nor are building contractors or lower-tier members of the building supply chain. This limitation is not detrimental to the study, however, as the authors only sought insight into the understanding of value held by practitioners who influence its debate in the construction projects to which the Design Quality Indicator and value agenda apply: namely, the construction of buildings. The low representation of the client in the sample is similarly justified as the client does not facilitate this process and therefore exerts limited control over it. Moreover, the plurality and diversity of the stakeholders that collectively constitute the client body precludes representation of a coherent population from which survey participants could be drawn to represent all clients and negates the validity of attempting to do so. An alternative, albeit less rigorous, view of the client is provided by Kelly (2007) who provides an empirical characterisation of generic client values argued to frame the judgement of value by most clients, rather than a definition of the client's understanding of value itself.

\section{Conclusions}

Practitioner understanding has been found to embody a broad understanding of value that retains the central subjective-objective construct. This insight confirmed that interpretation of the DQI fails to fully align with this understanding. This may explain dissonance between practitioners' awareness of their obligation to ensure projects provide value to their stakeholders and the policy imposition of the DQI as the vehicle to fulfil that obligation.

In response to the research question, it was concluded that construction practitioners' collective understanding of value reflects the value agenda but does not directly reflect either the benefits/ sacrifices model or the partial interpretation associated with the DQI; not does it fully reflect the four schools of value that exist independently to the DQI. This suggests that practitioners' broad understanding will, via their facilitation of dialogue, allow stakeholders to consider aspects of value not represented by the DQI. With current understanding, however, this will only be a partial exploration of the full nature of value.

This insight raises a further research question regarding the extent to which practitioners inject their full understanding of value into project dialogue. It is proposed that future work further unpacks each value continuum concept. Connected with insights into those value schools not yet fully represented in practitioners' understanding of value, this could inform development of an, albeit reductionist but still informative, replacement for the DQI to evaluate the presence of attributes of the dialogue necessary to consider value. As well as characterising practitioner performance in their value delivery role, the insight yielded by the tool would also help clients understand if they are unduly constraining practitioners' ability to lead the dialogue from which a project-specific understanding of value can emerge by, for example, considering the DQI capable of defining value when used alone. 


\section{References}

Alexander, C., Ishikawa, S., Silverstein, M., Jacobson, M., Fiksdahl-King, I., Angel, S. (1977). A Pattern Language, Oxford University Press, New York.

Arbulu, R., Tommelein, I., Walsh, K. and Hershauer, J. (2003). Value Stream Analysis of a ReEngineered Construction Supply Chain. Building Research \& Information, Vol. 31, No. 2, pp. 161-171.

Ares, G. and Deliza, R. (2010). Identifying important package features of milk desserts using free listing and word association, Food Quality and Preference, Vol. 21 No. 6, pp. 621-628.

Atkinson, R. (1999). Project management: cost, time and quality, two best guesses and a phenomenon, its time to accept other success criteria, International Journal of Project Management, Vol. 17 No. 6, pp. 337-342.

Barima, O.K.B. (2009). Crucial Tactical Variables for Value Delivery in Virtual Projects, Automation in Construction, Vol. 18, No. 7, pp. 875-880.

Beinat, E. (1997). Value Functions for Environmental Management, Kluwer Academic Publishers, AA Dordrecht.

Bernard, H.R. (2006). Research Methods in Anthropology: Qualitative and Quantitative Approaches (Fourth Edition), Altamira, Oxford.

Bernard, H.R. and Ryan, G.W. (2010). Analyzing Qualitative Data: Systematic Approaches, SAGE Publications, Thousand Oaks, CA.

Böhm-Bawerk, von, E. (1973). Value and Price: an Extract, Libertarian Press, South Holland, Illinois.

Borgatti, S.P. and Halgin, D. (2011). Elicitation Techniques for Cultural Domain Analysis. In J. Schensul and M. LeCompte, eds. The Ethnographer's Toolkit, Volume 3, Altamira Press, Walnut Creek.

Bousfield, W.A. (1953). The Occurrence of Clustering in the Recall of Randomly Arranged Associates, The Journal of General Psychology, Vol. 43, pp. 229-240.

Bousfield, W.A. and Barclay, W.D. (1950). The Relationship between Order and Frequency of Occurrence of Restricted Associative Responses, Journal of Experimental Psychology, Vol. 40 No. 5, pp. 643-647.

Brewer, D.D. (1995a). Cognitive Indicators of Knowledge in Semantic Domains, Journal of Quantitative Anthropology, Vol. 5 No. 2, pp. 107-128.

Brewer, D.D. (1995b). Patterns in the Recall of Persons in a Department of a Formal Organization, Journal of Quantitative Anthropology, Vol. 5 No. 4, pp. 255-284.

British Standards Institution (2000). BS EN 12973:2000 Value Management. British Standards Institution, London.

CABE (2005). Design Coding: Testing its use in England, CABE, London.

CABE (2006). Buildings and spaces: why design matters, Commission for Architecture and the Built Environment, London.

CABE (2007). Creating excellent secondary schools: A guide for clients, Commission for Architecture and the Built Environment, London.

CABE (2010). Creating excellent primary schools: A guide for clients, Commission for Architecture and the Built Environment, London.

Centre for Healthcare Design, (2002). Better Health Buildings: Good design is a commitment to a better quality of life for all, NHS Estates, Leeds.

Crowe, S.J. and Prescott, T.J. (2003). Continuity and Change in the Development of Category Structure: Insights from the Semantic Fluency Task, International Journal of Behavioral Development, Vol. 27 No. 5, pp. 467-479.

Dent, N. (1995). Good, in T. Honderich (ed), The Oxford Companion to Philosophy, Oxford University Press, Oxford, p. 322.

Dewulf, G. and van Meel, J. (2004). Sense and nonsense of measuring design quality. Building Research and Information, Vol. 32 No. 3, pp. 247-250. 
Edwards, R.B. (2010). Intrinsic and Extrinsic Value and Valuation, Journal of Value Inquiry, Vol. 13 No. 2, pp. 133-143.

Eley, J. (2004). Design Quality in Buildings, Building Research \& Information, Vol. 32 No. 3, pp. 255-260.

Gann, D.M., Salter, A.J. and Whyte, J.K. (2003). Design Quality Indicator as a Tool for Thinking, Building Research \& Information, Vol. 31 No. 5, pp. 318-333.

Gann, D. and Whyte, J. (2003). Design quality, its measurement and management in the built environment, Building Research \& Information, Vol. 31 No. 5, pp. 314-317.

Green, S.D. and Moss, G.W. (1998). Value management and post-occupancy evaluation: closing the loop, Facilities, Vol. 16 No. 1/2, pp. 34-39.

Grönroos, C. (2011). Value co-creation in service logic: A critical analysis. Marketing Theory, Vol. 11, No. 3, pp. 279-301.

Hartman, R.S. (1967). The Structure of Value: Foundations of Scientific Axiology, Southern Illinois University Press, Feffer and Simons, Inc.

Jahani, H. and El-Gohary, N. (2012). Value-Sensitive Construction: Value Discovery in Building Projects, in Construction Research Congress 2012: Construction Challenges in a Flat World, Proceedings of the 2012 Construction Research Congress, ASCE, West Lafayette, IN, 21-23 May, pp. 797-807.

Jaworska, N. and Chupetlovska-Anastasova, A. (2009). A Review of Multidimensional Scaling (MDS) and its Utility in Various Psychological Domains, Tutorials in Quantitative Methods for Psychology, Vol. 5 No. 1, pp. 1-10.

Kahneman, D. and Tversky, A. (1979). Prospect Theory: An Analysis of Decision under Risk, Econometrica, Vol. 47 No. 2, pp. 263-291.

Kahneman, D. (2011). Thinking, Fast and Slow, Allen Lane, London.

Kelly, J. and Male, S. (1993). Value Management in Design and Construction: The economic management of projects. E\&FN Spon, London.

Kelly, J., Male, S., Graham, D. (2004). Value Management of Construction Projects. Blackwell Science, Oxford.

Kelly, J. (2007). Making Client Values Explicit in Value Management Workshops. Construction Management and Economics, Vol. 25, No. 4, pp. 435-442.

Kemmer, S., Koskela, L., Sapountzis, S. and Codinhoto, R. (2011). A lean way of design and production for healthcare construction projects, in HaCIRIC International Conference 2017, Manchester, 26-28 September, pp. 176-189.

Keniger, M. (2004). Achieving design quality: from intent to implementation, Building Research \& Information, Vol. 32 No. 3, pp. 251-254.

Leiringer, R., Green, S. and Raja, J. (2009). Living up to the value agenda: the empirical realities of through-life value creation in construction, Construction Management and Economics, Vol. 27 No. 3, pp. 271-285.

Lindhard, S. and Wandahl, S. (2012). Adding Production Value Through Application of Value Based Scheduling, in RICS COBRA 2012, Proceedings of the Construction, Building and Real Estate Conference, 11-13 September, Las Vegas, Nevada, pp. 544-551.

Male, S., Kelly, J., Fernie, S., Grönqvist, M., Bowles, G. (1998). The value management benchmark: A good practice framework for clients and practitioners. Thomas Telford, London.

Male, S., Kelly, J., Grönqvist, M. and Graham, D. (2007). Managing value as a management style for projects, International Journal of Project Management, Vol. 25, pp. 107-114.

Miles, L.D. (1961). Techniques of Value Analysis and Engineering. McGraw Hill, New York.

Mulgan, G. (2005). Public value: Physical capital and the potential of value maps, in CABE (ed.) Physical capital: How great places boost public value, Commission for Architecture and the Built Environment, London, pp. 8-27.

Nicolini, D. (2002). In search of "project chemistry," Construction Management and Economics, Vol. 20 No. 2, pp. 167-177.

Nikkhah, R. (2011). Building Schools for the Future plans to be scrapped, The Telegraph, 3 July. 
O'Keeffe, D.J., Thomson, D. and Dainty, A. (2011). Beyond Scoring: Facilitating enhanced evaluation of the design quality of NHS healthcare buildings, in HaCIRIC International Conference 2017, Manchester, 26-28 September, pp. 68-79.

Payne, A.F., Storbacka, K., Frow, P. (2007). Managing the Co-Creation of Value, Journal of the Academy of Marketing Science, Vol. 36, No. 1, pp. 83-96.

Pearce, D. and Özdemiroglu, E. (2002). Economic Valuation with Stated Preference Techniques: Summary guide, Department for Transport, Local Government and the Regions, London.

Pirsig, R.M. (1974). Zen and the Art of Motorcycle Maintenance: An Inquiry into Values. Bodley Head, London.

Rescher, N. (2004). Value Matters: Studies in Axiology. Ontos Verlag, Frankfurt.

Rogers, D. (2010). Minister favours 'sheds' for hospitals: Maude emphasises future, Building Design, 1975, 22 July.

SAVE International (2007). Value methodology standard and body of knowledge. SAVE International.

Schrauf, R.W. and Sanchez, J. (2008). Using Freelisting to Identify, Assess, and Characterize Age Differences in Shared Cultural Domains, Journal of Gerontology: SOCIAL SCIENCES, Vol. 63B No. 6, pp. S385-S393.

Schrauf, R.W. and Sanchez, J. (2010). Age Effects and Sample Size in Free Listing, Field Methods, Vol. 22, No. 1, pp. 70-87.

Sennett, R. (2008). The Craftsman. Allen Lane, London.

Slack, R. (1999). The Lean Value Principle in Military Aerospace Product Development. The Lean Aerospace Initiative Report Series RP99-01-76, Lean Aerospace Initiative Center for Technology, Policy, and Industrial Development, Massachusetts Institute of Technology, Cambridge, MA.

Smith, J.W. (1948). Intrinsic and Extrinsic Good, Ethics, Vol. 58, No. 3, pp. 195-208.

Spencer, N.C. and Winch, G.M. (2002). How buildings add value for clients, Construction Industry Council \& Thomas Telford, London.

Sutrop, U. (2001). List Task and a Cognitive Salience Index, Field Methods, Vol. 13 No. 3, pp. 263-276.

Thomson, D., Austin, S.A., Devine-Wright, H. and Mills, G.R. (2003). Managing value and quality in design, Building Research \& Information, Vol. 31 No. 5, pp. 334-345.

Thomson, D.S. and Austin, S.A. (2006). Using VALiD to Understand Value from the Stakeholder Perspective, in Proceedings, SAVE International 46th Annual Conference, SAVE International, Savannah GA.

Thomson, D., Kaka, A., Pronk, L. and Alalouch, C. (2011). The Benefits Quantification Method: A practical approach to engaging stakeholders in the judgement of benefits realisation, in Proceedings, HaCIRIC International Conference 2017, HaCIRIC, 26-28 September, Manchester, pp. 224-243.

Thomson, D., Kaka, A., Pronk, L. and Alalouch, C. (2012). The use of freelisting to elicit stakeholder understanding of the benefits sought from healthcare buildings, Construction Management and Economics, Vol. 30 No. 4, pp. 309-323.

Thyssen, M.H., Emmitt, S., Bonke, S., Kirk-Christoffersen, A. (2010). Facilitating Client Value Creation in the Conceptual Design Phase of Construction Projects: A Workshop Approach, Architectural Engineering and Design Management, Vol. 6 No. 1, pp. 18-30.

Thyssen, M.H. (2011). Facilitating Value Creation and Delivery in Construction Projects, PhD Thesis, Department of Management Engineering, Technical University of Denmark.

Uusküla, M. and Sutrop, U. (2007). Preliminary Study of Basic Colour Terms in Modern Hungarian, Linguistica Uralica, Vol. 43 No. 2, pp. 102-123.

Vargo, S.L., Maglio, P.P. and Akaka, M.A. (2008). On value and value co-creation: A service systems and service logic perspective, European Management Journal, Vol. 26 No. 3, pp. 145-152.

Vargo, S.L. and Lusch, R.F. (2008). Service Dominant Logic: Continuing the Evolution, Journal of the Academy of Marketing Science, Vol. 36, No. 1, pp. 1-10. 
Vitruvius (2001). in I.D. Rowland and T.N. Howe (eds), Ten Books on Architecture, Cambridge University Press, Cambridge.

Volker, L., Lauche, K., Heintz, J.L. and de Jonge, H. (2008). Deciding about design quality: design perception during a European tendering procedure, Design Studies, Vol. 29, pp. 387-409.

Volker, L. (2010). Deciding about Design Quality: Value judgements and decision making in the selection of architects by public clients under European tendering regulations, PhD Thesis, Delft, Delft University of Technology.

Weller, S.C. and Romney, A.K. (2009). Systematic Data Collection. Quantitative Research Methods, Volume 10, Sage Publications, Newbury Park, California.

Westbury, P. (2007). A sense of place: What residents think of their new homes J. Birch, ed., London, Commission for Architecture and the Built Environment.

Winkler-Rhoades, N., Medin, D., Waxman, S.R., Woodring, J. and Ross, N.O. (2010). Naming the Animals that Come to Mind: Effects of Culture and Experience on Category Fluency, Journal of Cognition and Culture, Vol. 10, pp. 205-220.

Womack, J.P. and Jones, D.T. (2003). Lean thinking: Banish waste and create wealth in your corporation. Touchstone, London.

Yu, A.G., Flett, P.D. and Bowers, J.A. (2005). Developing a value-centred proposal for assessing project success. International Journal of Project Management, Vol. 23, pp. 428-436.

Zemke, D.M.V. and Pullman, M. (2008). Assessing the value of good design in hotels, Building Research \& Information, Vol. 36 No. 6, pp. 543-556. 


\begin{tabular}{|c|c|c|}
\hline Cluster & $\begin{array}{l}\text { Salient } \\
\text { Concept }\end{array}$ & Constituent Elicited Terms \\
\hline \multirow[t]{2}{*}{1} & Durability & $\begin{array}{l}125 \text { year life; cycle; durability }(x 2) \text {; lasting }(x 2) \text {; life; life time; lifecycle; } \\
\text { long lasting; longevity }(x 2) \text {; robust }(x 2) \text {; robustness; solid }(x 2) \text {; strong; } \\
\text { weathering; well built }\end{array}$ \\
\hline & Cost & $\begin{array}{l}\text { budgets; capital costs; cost (x23); cost control; cost effective; costs; } \\
\text { economic; economic whip!; low capital base; not over budget; spend; } \\
\text { unprofitable works }\end{array}$ \\
\hline \multirow[t]{4}{*}{2} & Market Price & $\begin{array}{l}\text { acquisition; economic value; exchanging; price (x8); residual (values); } \\
\text { sale; valuable }\end{array}$ \\
\hline & Money & golds; money (x14) \\
\hline & Client & $\begin{array}{l}\text { client }(\times 5) \text {; client base; client perspective; consumer control; customer; } \\
\text { customers; enlightened client; happy client; quality of client }\end{array}$ \\
\hline & Quality & luxuries; perfect; quality (x26) \\
\hline \multirow[t]{5}{*}{3} & Design & $\begin{array}{l}\text { alternative design; architectural design; awards for design; classic; } \\
\text { design (x15); design quality; engineering; engineering input; form; } \\
\text { geometrical; good design; plans; scale; skills of the designer; } \\
\text { thoughtful design }\end{array}$ \\
\hline & Sustainable & $\begin{array}{l}\text { environment (x8); environmental compliance; environmentally aware; } \\
\text { pollution (non); sustainability (x5); sustainable (x3); sustainable } \\
\text { development; sustainable environment }\end{array}$ \\
\hline & Aesthetics & $\begin{array}{l}\text { aesthetic }(x 2) \text {; aesthetic pleasing; aesthetics (x2); ambience; } \\
\text { appearance }(x 3) \text {; beauty; colour (x6); looks; looks good; nice ceilings; } \\
\text { well-presented }\end{array}$ \\
\hline & Functionality & $\begin{array}{l}\text { accommodating; activities; ease of use (x2); firmness; function (x3); } \\
\text { functional (x4); functionality; functions; suitability for purpose; usability; } \\
\text { usable; usage; useful }\end{array}$ \\
\hline & Materials & $\begin{array}{l}\text { best materials; elements; finish; materials (x14); natural materials; } \\
\text { quality finishes; quality materials; standard of materials; timber }\end{array}$ \\
\hline \multirow[t]{2}{*}{4} & Benefit & benefit $(x 8)$; benefits $(x 3)$; bonus \\
\hline & Worth & long term value; objects; valuation; value $(x 3)$; value not $£$; worth $(x 3)$ \\
\hline \multirow[t]{2}{*}{5} & Management & $\begin{array}{l}\text { asset management; inspections; manage; management }(x 4) \text {; } \\
\text { management of delivery; managing; monitoring of work; poor } \\
\text { organisation; process; project focus; project management }(x 2) \text {; site } \\
\text { management; supervision; well managed }\end{array}$ \\
\hline & Time & $\begin{array}{l}\text { deadline; early; endless; on time; on time completion; over time; } \\
\text { overdue; penalty; programme; time (x8); time scale (x2); unrealistic } \\
\text { deadlines }\end{array}$ \\
\hline
\end{tabular}

Appendix: The Composition of Associative Clusters and their Constituent Salient Concepts 